\title{
Educar en la Universidad de hoy
}

Autores: Fernando Gil Cantero y David Reyero García

Editorial: Encuentro.

Año de publicación: 2015.

Número de páginas: 128.

ISBN: 978-84-9055-109-7

Renovar significa llevar algo a su primer estado. Este es el esfuerzo principal de estas páginas. Devolver a la universidad a su primer estado, a los fines que le son propios, no por un empeño tradicionalista, sino por volver a hacer nuevo aquello que merece serlo. El libro consta de dos partes. La primera (capítulos 1 a 4) sobre la enseñanza en la universidad y la segunda (capítulos 1 a 7) sobre la vida universitaria.

En el primer capítulo, titulado La Universidad en la encrucijada, José María Barrio, ofrece una revisión sobre los problemas más comunes que sufre la universidad de hoy. El autor nos recuerda que a la universidad no se le ha encomendado el trabajo de enseñar cosas para resolver embarazos empíricos, sino de aprender a dialogar con la realidad y a vivir en ella. Esto, en la labor de los profesores, se concreta en tres tareas: estudiar mucho, preparar lo mejor posible las clases y atender bien a los alumnos. El autor se pregunta: ¿Tendremos que asumir que la universidad es ahora un suministro de pasaportes para el mercado laboral? ¿O salvando el curso de lo natural se puede rescatar algo de lo que la Academia nació siendo?.

En el segundo capítulo bajo el título Hacia una Pedagogía universitaria. Los seminarios de lectura en la Universidad, los profesores Fernando Gil y Alberto Sánchez contestan a las preguntas anteriores asegurando que de la universidad se esperan ambos fines. Será precisamente la suma de esta formación profesional y humanística lo que va a dar unidad de sentido al ser profesional. Gil y Sánchez proponen los seminarios de lectura como islotes para náufragos, como espacios donde profesores y alumnos se junten para reconocer y pensar el mejor concepto explicativo, el argumento que más fielmente se corresponde con la realidad.

En el tercer capítulo titulado Los Proyectos de Aprendizaje Servicio Solidario (ApS) en la Universidad, Mónica Fontana, Carlos Peláez y Araceli del Pozo nos muestran otro ejemplo de cómo generar un espacio auténticamente universitario, que no ponga en disputa la profesionalización y la formación humanística. Se trata de los proyectos de Aprendizaje Servicio Solidario. Esta propuesta es a la vez una filosofía, una metodología y una pedagogía que combina el razonamiento crítico, el aprendizaje cooperativo, el compromiso cívico y las competencias profesionales.

El cuarto capítulo, escrito por Juan García-Gutiérrez, con el título La Universidad en la sociedad red. Entre el mercado y los derechos humanos nos abre los ojos ante las bondades de la enseñanza online. García nos revela que hay dos razones por las cuales tenemos enseñanza online hoy día: razones pedagógicas e institucionales. La universidad en red, podrá seguir por tanto dos enfoques: el competitivo y el cultural y de desarrollo de la ciudadanía global. Si se acentúa este último enfoque, la universidad 
puede hacer gala del adjetivo que mejor le define, a saber, universal, y promover así una ciudadanía no preocupada solo de asuntos nacionales, sino proyectada a un futuro común.

El quinto capítulo, con el título Ser profesor en la Universidad hoy escrito por los profesores Bianca Thoilliez y Javier Valle, ofrece algunas evidencias y reflexiones sobre lo que significa ser profesor en la universidad hoy desde dos ejes: la administración de la vida académica y la investigación orientada a resultados. Explican que la agenda política europea ha supuesto la apertura a nuevos objetos susceptibles de ser gobernados. Así también, exponen cómo la supervivencia en la universidad depende del impacto de nuestras publicaciones según estándares de calidad. No obstante, los autores nos dan tres claves para concentrarnos en lo importante: curiosidad, imaginación y perseverancia.

El sexto capítulo de Francisco Esteban, titulado El grupo de hombres y mujeres educados en la universidad trata de dar respuesta a la pregunta de Ortega, ¿para qué está la universidad? con sus cuatro virtudes: el esfuerzo, la prudencia, la autenticidad y la elegancia. Esteban nos delata que la universidad no ha de ser un espacio de adaptación al mercado laboral, con títulos universitarios, sino que la universidad ha de orientarse hacia algo, y la universidad tiene que ver con el cultivo de determinadas virtudes que se adquieren en pocos lugares más que no sea en la universidad.

El séptimo capítulo titulado De corazón a corazón. Ideas de John Henry Newman para la Universidad por venir, viene de la mano de David Reyero y David Luque, que rescatan una serie de conferencias del cardenal Newman sobre la idea de la universidad, y nos exponen en qué medida las aportaciones de este pensamiento "viejo" resulta más pertinente que nunca. En particular, rescatan tres ideas del cardenal que son reveladoras para nuestro tiempo: (1) no damos clase para entretener, sino que el profesor ha de transmitir algo al estudiante, (2) hay un orden en la realidad, de manera que hay un correlato entre los estudios y (3) la universidad ha de crear un hábito de pensamiento, con orden y sistema.

A lo largo del libro se pueden destilar tres notas comunes que distinguen esta obra de otras de temática similar: 1. Una hipótesis de sentido como premisa. Este libro ofrece el posicionamiento y la convicción de que merece la pena estudiar, investigar, escribir y enseñar para descubrir los argumentos que mejor describen la realidad. 2. La transmisión de saberes como medio.Cada autor rescata la importancia de que sólo se puede enseñar lo que se sabe y lo que se es. Conocimientos y argumentos de cada disciplina que cada profesor ha de pensar con rigor, y que ha de hacerlos suyos para poder transmitirlos. 3. La humanización como meta. Fue Kant el que describió la tarea educativa como la humanización del hombre. Los autores del libro comparten la tensión antropológica de preguntarse quién es el ser humano, y qué es verdaderamente humano. El ser humano, por acto cultural, no natural, podrá tender a su humanización y por la misma dinámica a su deshumanización. De ahí la meta compartida de entender quién es el hombre para que la educación esté a la altura de esta exigencia.

Tania Alonso Sainz Universidad Autónoma de Madrid 